\title{
Impact of molecular imaging on the diagnostic process in a memory clinic
}

\author{
Citation for published version (APA):
}

Ossenkoppele, R., Prins, N. D., Pijnenburg, Y. A. L., Lemstra, A. W., van der Flier, W. M., Adriaanse, S. F., Windhorst, A. D., Handels, R. L. H., Wolfs, C. A. G., Aalten, P., Verhey, F. R. J., Verbeek, M. M., van Buchem, M. A., Hoekstra, O. S., Lammertsma, A. A., Scheltens, P., \& van Berckel, B. N. M. (2013). Impact of molecular imaging on the diagnostic process in a memory clinic. Alzheimer's \& Dementia, 9(4), 414-421. https://doi.org/10.1016/j.jalz.2012.07.003

\section{Document status and date:}

Published: 01/07/2013

DOI:

10.1016/j.jalz.2012.07.003

Document Version:

Publisher's PDF, also known as Version of record

\section{Document license:}

Taverne

\section{Please check the document version of this publication:}

- A submitted manuscript is the version of the article upon submission and before peer-review. There can be important differences between the submitted version and the official published version of record.

People interested in the research are advised to contact the author for the final version of the publication, or visit the DOI to the publisher's website.

- The final author version and the galley proof are versions of the publication after peer review.

- The final published version features the final layout of the paper including the volume, issue and page numbers.

Link to publication

\footnotetext{
General rights rights.

- You may freely distribute the URL identifying the publication in the public portal. please follow below link for the End User Agreement:

www.umlib.nl/taverne-license

Take down policy

If you believe that this document breaches copyright please contact us at:

repository@maastrichtuniversity.nl

providing details and we will investigate your claim.
}

Copyright and moral rights for the publications made accessible in the public portal are retained by the authors and/or other copyright owners and it is a condition of accessing publications that users recognise and abide by the legal requirements associated with these

- Users may download and print one copy of any publication from the public portal for the purpose of private study or research.

- You may not further distribute the material or use it for any profit-making activity or commercial gain

If the publication is distributed under the terms of Article $25 \mathrm{fa}$ of the Dutch Copyright Act, indicated by the "Taverne" license above, 


\title{
Impact of molecular imaging on the diagnostic process in a memory clinic
}

\author{
Rik Ossenkoppele ${ }^{\mathrm{a}, \mathrm{b}, *}$, Niels D. Prins ${ }^{\mathrm{a}}$, Yolande A. L. Pijnenburg ${ }^{\mathrm{a}}$, Afina W. Lemstra ${ }^{\mathrm{a}}$, \\ Wiesje M. van der Flier ${ }^{\mathrm{a}, \mathrm{c}}$, Sofie F. Adriaanse ${ }^{\mathrm{a}, \mathrm{b}}$, Albert D. Windhorst ${ }^{\mathrm{b}}$, Ron L. H. Handels ${ }^{\mathrm{d}}$, \\ Claire A. G. Wolfs ${ }^{\mathrm{d}}$, Pauline Aalten ${ }^{\mathrm{d}}$, Frans R. J. Verhey ${ }^{\mathrm{d}}$, Marcel M. Verbeek ${ }^{\mathrm{e}, \mathrm{f}}$, \\ Mark A. van Buchem ${ }^{\mathrm{f}, \mathrm{g}}$, Otto S. Hoekstra ${ }^{\mathrm{b}}$, Adriaan A. Lammertsma ${ }^{\mathrm{b}}$, Philip Scheltens ${ }^{\mathrm{a}}$, \\ Bart N. M. van Berckel ${ }^{\mathrm{b}}$ \\ ${ }^{a}$ Department of Neurology and Alzheimer Center, VU University Medical Center, Amsterdam, The Netherlands \\ ${ }^{b}$ Department of Nuclear Medicine and PET Research, VU University Medical Center, Amsterdam, The Netherlands \\ ${ }^{c}$ Department of Epidemiology and Biostatistics, VU University Medical Center, Amsterdam, The Netherlands \\ ${ }^{d}$ Department of Psychiatry and Psychology, School for Mental Health and Neuroscience, Maastricht University Medical Centre, Alzheimer Centre Limburg, \\ Maastricht, The Netherlands \\ ${ }^{e}$ Department of Neurology, Radboud University, Nijmegen Medical Centre, Nijmegen, The Netherlands \\ ${ }^{f}$ Department of Laboratory Medicine, Radboud University, Nijmegen Medical Centre, Nijmegen, The Netherlands \\ ${ }^{g}$ Department of Radiology, Leiden University Medical Center, Leiden, The Netherlands
}

Abstract

Background: $\left[{ }^{11} \mathrm{C}\right]$ Pittsburgh compound $\mathrm{B}\left(\left[{ }^{11} \mathrm{C}\right] \mathrm{PIB}\right)$ and $\left[{ }^{18} \mathrm{~F}\right]$-2-fluoro-2-deoxy-D-glucose $\left(\left[{ }^{18} \mathrm{~F}\right]\right.$ FDG) PET measure fibrillar amyloid- $\beta$ load and glucose metabolism, respectively. We evaluated the impact of these tracers on the diagnostic process in a memory clinic population.

Methods: One hundred fifty-four patients underwent paired dynamic $\left[{ }^{11} \mathrm{C}\right] \mathrm{PIB}$ and static $\left[{ }^{18} \mathrm{~F}\right] \mathrm{FDG}$ PET scans shortly after completing a standard dementia screening. Two-year clinical follow-up data were available for 39 patients. Parametric PET images were assessed visually and results were reported to the neurologists responsible for the initial diagnosis. Outcome measures were (change in) clinical diagnosis and confidence in that diagnosis before and after disclosing PET results.

Results: [ ${ }^{11} \mathrm{C}$ ]PIB scans were positive in 40 of $66(61 \%)$ patients with a clinical diagnosis of Alzheimer's disease (AD), 5 of 18 (28\%) patients with frontotemporal dementia (FTD), 4 of $5(80 \%)$ patients with Lewy body dementia, and 3 of $10(30 \%)$ patients with other dementias. $\left[{ }^{18} \mathrm{~F}\right] \mathrm{FDG}$ uptake patterns matched the clinical diagnosis in 38 of $66(58 \%)$ of AD patients, and in 6 of $18(33 \%)$ FTD patients. PET results led to a change in diagnosis in $35(23 \%)$ patients. This only occurred when prior diagnostic certainty was $<90 \%$. Diagnostic confidence increased from $71 \pm 17 \%$ before to 87 $\pm 16 \%$ after PET $(p<.001)$. Two-year clinical follow-up $(n=39)$ showed that $\left[{ }^{11} \mathrm{C}\right] \mathrm{PIB}$ and $\left[{ }^{18} \mathrm{~F}\right]$ FDG predicted progression to AD for patients with mild cognitive impairment, and that the diagnosis of dementia established after PET remained unchanged in $96 \%$ of patients.

Conclusions: In a memory clinic setting, combined $\left[{ }^{11} \mathrm{C}\right] \mathrm{PIB}$ and $\left[{ }^{18} \mathrm{~F}\right] \mathrm{FDG}$ PET are of additional value on top of the standard diagnostic work-up, especially when prior diagnostic confidence is low. (C) 2013 The Alzheimer's Association. All rights reserved.

Keywords: $\quad$ PET; $\left[{ }^{11}\right.$ C $]$ PIB; $\left[{ }^{18}\right.$ F $]$ FDG; Memory clinic; Alzheimer's disease; FTD; Lewy body dementia; MCI; SMC

\section{Introduction}

The diagnosis of patients with cognitive and/or behavioral symptoms can be complicated as different types of

*Corresponding author. Tel.: 44-2442-6085; Fax: 44-2442-6088.

E-mail address: r.ossenkoppele@vumc.nl neurodegenerative disorders show overlap in clinical presentation, particularly in patients with an early onset of disease $(<65$ years) [1]. Furthermore, it is difficult to identify patients in a prodromal stage of Alzheimer's disease (AD) or other forms of dementia based on clinical symptoms alone. Improvement of early and differential 
diagnosis is desirable, especially in view of emerging disease-modifying agents. Over the past decades, several biomarkers have been developed to increase diagnostic accuracy in neurodegenerative diseases. These biomarkers have caused a major paradigm shift and have been incorporated in recently revised criteria that aim for more accurate and earlier diagnosis of $\mathrm{AD}$, frontotemporal dementia (FTD), and dementia with Lewy bodies (DLB) [2-6].

Molecular imaging biomarkers most frequently used in the diagnosis of dementia are $\left[{ }^{18} \mathrm{~F}\right]$-2-fluoro-2-deoxy-D-glucose $\left(\left[{ }^{18} \mathrm{~F}\right] \mathrm{FDG}\right)$ and $\left[{ }^{11} \mathrm{C}\right]$ Pittsburgh compound $\mathrm{B}\left(\left[{ }^{11} \mathrm{C}\right]\right.$ $\mathrm{PIB})$, which can be imaged using positron emission tomography (PET). $\left[{ }^{18} \mathrm{~F}\right] \mathrm{FDG}$ is the more established tracer and provides a measure of metabolic activity of the brain. $\left[{ }^{18} \mathrm{~F}\right]$ FDG does not directly measure pathology, but rather the extent of metabolic impairment predicts cognitive decline, and is closely related to disease severity [7-9]. Mapping the pattern of glucose hypometabolism has high sensitivity (94\%) for diagnosing $\mathrm{AD}$, but specificity is lower (73\%), as other neurodegenerative diseases can induce a decrease in glucose metabolism resembling the pattern seen in $\mathrm{AD}$ $[10-12]$. Reading $\left[{ }^{18} \mathrm{~F}\right]$ FDG images requires a well-trained eye, and even then only moderate interrater reliability is accomplished [13,14].

More recently, $\left[{ }^{11} \mathrm{C}\right] \mathrm{PIB}$ [15] became available for in vivo detection of fibrillary amyloid plaques, a neuropathologic hallmark of AD. Probing the underlying neuropathologic substrate may be helpful in identifying the correct type of dementia, particularly in patients with an atypical presentation [16]. $\left[{ }^{11} \mathrm{C}\right] \mathrm{PIB}$ discriminates $\mathrm{AD}$ patients from cognitively normal elderly $[15,17,18]$, is a strong predictor of progression of mild cognitive impairment (MCI) to $\mathrm{AD}$ [19-21], and distinguishes AD reasonably well from other forms of dementia such as FTD [16,22] and vascular dementia (VaD) [23]. Patients with DLB, however, show positive $\left[{ }^{11} \mathrm{C}\right] \mathrm{PIB}$ scans in up to $89 \%$ of cases [24], which corresponds to increased amyloid burden found at postmortem examination in the majority of DLB patients [25]. Visual assessment of parametric $\left[{ }^{11} \mathrm{C}\right] \mathrm{PIB}$ images is straightforward and shows a high level of agreement between readers [14].

The current literature on $\left[{ }^{18} \mathrm{~F}\right] \mathrm{FDG}$ and especially $\left[{ }^{11} \mathrm{C}\right]$ PIB PET typically consists of comparisons of highly selected diagnostic groups. In general, these studies show good correspondence between clinical diagnosis and neuroimaging results. The potential lack of variation in pretest diagnostic certainty, however, may overestimate this concordance and may actually be lower in a more representative sample of a memory clinic population. The aim of the present study was therefore to assess the impact of $\left[{ }^{11} \mathrm{C}\right] \mathrm{PIB}$ and $\left[{ }^{18} \mathrm{~F}\right] \mathrm{FDG}$ PET on the diagnostic process in a large sample of patients from a memory clinic, encompassing a wide spectrum of cognitive and/or behavioral symptoms.

\section{Methods}

\subsection{Subjects and diagnostic procedure}

Between March 2009 and September 2011, 154 patients were included from the outpatient memory clinic of the VU University Medical Center. All patients underwent standard diagnostic work-up for dementia consisting of medical history, informant based history, physical and neurologic examinations, screening laboratory tests, brain magnetic resonance imaging (MRI), and neuropsychologic testing [26]. This was followed by paired $\left[{ }^{11} \mathrm{C}\right] \mathrm{PIB}$ and $\left[{ }^{18}\right.$ F]FDG PET scans. To ensure substantial variation in pretest diagnostic certainty, patients were recruited from two cohorts. One hundred nine patients were enrolled in the Center for Translational Molecular Medicine (CTMM) Leiden Alzheimer Research Netherlands (LeARN) project. The aim of this project is to evaluate the cost-effectiveness of ancillary investigations in a memory clinic setting, encompassing a wide spectrum of cognitive and/or behavioral symptoms. Patients with a Mini-Mental State Examination (MMSE) score of $\geq 20$ and a maximum clinical dementia rating (CDR) of 1, without major neurologic and psychiatric disorders, recent vascular events, and excessive substance abuse, could participate in LeARN. In a second group of 45 patients, $\left[{ }^{11} \mathrm{C}\right] \mathrm{PIB}$ and $\left[{ }^{18} \mathrm{~F}\right] \mathrm{FDG}$ PET scans were performed in case of substantial uncertainty about the diagnosis after the standard diagnostic work-up. The aforementioned inclusion criteria did not apply to the latter group of patients. A clinical diagnosis was made by consensus of a multidisciplinary team using established clinical criteria [27-31]. Diagnostic categories were AD, FTD, VaD, DLB, dementia-other (i.e., corticobasal degeneration [CBD] and progressive supranuclear palsy [PSP]), MCI, subjective memory complaints (SMC), psychiatry, and neurologyother (i.e., normal pressure hydrocephalus). In December 2011, 2-year clinical follow-up data (consisting of neurologic and neuropsychologic reevaluation, without neuroimaging) were available for 39 patients. All patients gave written informed consent after they had received a complete written and verbal description of the study. The medical ethics review committee of the VU University Medical Center approved the study.

\subsection{PET imaging and analysis}

PET procedures have been reported elsewhere [26]. Briefly, PET scanning was performed on an ECAT Exact HR + scanner (Siemens/CTI, Knoxville, TN). After a 10-minute transmission scan, a dynamic 90-minute emission scan was started simultaneously with an intravenous injection of $367 \pm 43 \mathrm{MBq}\left[{ }^{11} \mathrm{C}\right] \mathrm{PIB}$. After coregistration of the MRIs to the corresponding PET images, the data were further analyzed using PVELab [32]. Regions of interest (ROIs) were projected onto nondisplaceable binding 
potential $\left(\mathrm{BP}_{\mathrm{ND}}\right)$ images of $\left[{ }^{11} \mathrm{C}\right] \mathrm{PIB}$. These images were generated by applying a two-step basis-function implementation of the simplified reference tissue model (RPM2) [33]. For 12 patients, standardized uptake value ratio (SUVr) images of $\left[{ }^{11} \mathrm{C}\right] \mathrm{PIB}$ for the interval between 60 and 90 minutes [34], rather than $\mathrm{BP}_{\mathrm{ND}}$ images, were generated because of patient movement and/or technical issues. Cerebellar gray matter was chosen as reference tissue.

After an interval of at least 2 hours to allow for decay of $\left[{ }^{11} \mathrm{C}\right] \mathrm{PIB}$, an intravenous bolus of approximately $185 \mathrm{MBq}$ of $\left[{ }^{18} \mathrm{~F}\right]$ FDG was administered. All subjects rested for 15 minutes before and for 35 minutes after injection with eyes closed and ears unplugged in a dimly lit room with minimal background noise. Next, patients underwent a 10-minute transmission scan followed by a 15-minute emission scan. Parametric SUVr images were extracted from the interval between 45 and 60 minutes after injection. In addition, $\left[{ }^{18} \mathrm{~F}\right] \mathrm{FDG}$ scans were analyzed using the PMOD Alzheimer's discrimination (PALZ) tool [35]. Briefly, the PALZ tool compares age-corrected $\left[{ }^{18}\right.$ F]FDG uptake with predicted uptake. The $t$ values of all abnormal voxels within a predefined AD mask are summed, yielding an $\mathrm{AD} t$-sum that automatically classifies the scan into either normal or abnormal.

For both tracers, T1-weighted MRI (3T Signa HDxt; General Electric, Milwaukee, WI) scans were used for coregistration and segmentation. Due to tracer synthesis failure, 21 patients did not undergo $\left[{ }^{11} \mathrm{C}\right] \mathrm{PIB}$ and $\left[{ }^{18} \mathrm{~F}\right] \mathrm{FDG}$ PET scans on the same day but within an interval of, at most, 4 weeks. $\left[{ }^{11} \mathrm{C}\right] \mathrm{PIB}$ and $\left[{ }^{18} \mathrm{~F}\right]$ FDG PET scans were performed $2 \pm 1$ months after dementia screening.

\subsection{Visual assessment of parametric $\left[{ }^{11} \mathrm{C}\right] P I B$ and $\left[{ }^{18} \mathrm{~F}\right]$ FDG images}

$\mathrm{BP}_{\mathrm{ND}}(n=142)$ and $\operatorname{SUVr}(n=12)$ images of $\left[{ }^{11} \mathrm{C}\right] \mathrm{PIB}$ and SUVr images of $\left[{ }^{18} \mathrm{~F}\right] \mathrm{FDG}$ were assessed visually by an experienced nuclear medicine physician (B.v.B.). $\left[{ }^{11} \mathrm{C}\right] \mathrm{PIB}$ PET scans were rated as either PIB-positive $\left(\mathrm{PIB}^{+}\right.$; binding in more than one cortical brain region; i.e., frontal, parietal, temporal, or occipital) or PIB-negative ( $\mathrm{PIB}^{-}$, predominantly white matter binding). For $\left[{ }^{18} \mathrm{~F}\right] \mathrm{FDG}$ PET scans, the reader had access to both the original images and the results of the PALZ tool. The nuclear medicine physician made the final decision. $\left[{ }^{18}\right.$ F]FDG PET scans were interpreted as either normal or deviant and suggestive for $\mathrm{AD}$ (posterior cingulate and parietotemporal hypometabolism), FTD (frontotemporal metabolic impairment), DLB (occipital hypometabolism with relatively intact posterior cingulate gyrus), or dementiaother (PSP: mesenchepalon, prefrontal, caudate nucleus, and thalamus hypometabolism; CBD: asymmetric hypometabolism with involvement of the basal ganglia). $\left[{ }^{11} \mathrm{C}\right] \mathrm{PIB}$ and $\left[{ }^{18} \mathrm{~F}\right] \mathrm{FDG}$ scans were assessed together and the reader had access to the clinical differential diagnosis.

\subsection{Assessment of impact PET on diagnostic process}

After clinical assessment, that is, prior to PET, one of the neurologists (either N.D.P., A.W.L., Y.A.L.P., or P.S.) indicated the most probable (consensus) diagnosis on a questionnaire (refer to form in supplementary material). It was mandatory for the neurologists to select a diagnosis. In addition, the level of diagnostic certainty was estimated on a scale ranging from $0 \%$ to $100 \%$. Next, PET scanning and subsequent rating was performed and the scans were discussed at a monthly meeting in the presence of the neurologists. Subsequently, the most probable diagnosis and corresponding diagnostic certainty were indicated again by the neurologist responsible for the initial diagnosis, now taking into account the findings on PET in addition to the clinical information. Furthermore, it was indicated whether both tracers, $\left[{ }^{11} \mathrm{C}\right] \mathrm{PIB}$ alone, $\left[{ }^{18} \mathrm{~F}\right] \mathrm{FDG}$ alone, or none, contributed to the diagnostic process. To specify the utility of the individual tracers, the neurologists were asked whether $\left[{ }^{11} \mathrm{C}\right] \mathrm{PIB}$ and $\left[{ }^{18} \mathrm{~F}\right] \mathrm{FDG}$ improved, confused, or had only little or no effect on their understanding of a patient's disease.

\subsection{Statistics}

Differences in baseline values between groups were assessed using analysis of variance (ANOVA), Kruskal-Wallis tests, and $\chi^{2}$ tests, where appropriate. Paired-samples $t$ tests were used to assess change of diagnostic certainty after PET. Independent-sample $t$ tests were used to assess differences in diagnostic certainty prior to PET between AD patients with $\mathrm{PIB}^{+}$and $\mathrm{PIB}^{-}$PET scans, and between patients with and without diagnostic alteration after PET.

\section{Results}

\subsection{Subjects}

After the initial standard dementia work-up, patients received the following clinical diagnoses: $\mathrm{AD}(n=66)$; MCI $(n=30)$; SMC $(n=15) ;$ FTD $(n=18) ;$ DLB $(n=$ $5)$; dementia-other $(n=10)$; psychiatry $(n=6)$; and neurology-other $(n=4)$. Characteristics according to diagnostic group are presented in Table 1. Diagnostic certainty did not differ between groups prior to PET.

\subsection{Visual PET ratings}

Table 1 also provides visual ratings of $\left[{ }^{11} \mathrm{C}\right] \mathrm{PIB}$ and $\left[{ }^{18}\right.$ F]FDG PET scans. Most AD patients had PIB ${ }^{+}$scans $(61 \%)$ and most patients with non-Alzheimer's dementia had $\left[{ }^{11} \mathrm{C}\right] \mathrm{PIB}^{-}$scans $(67 \%)$. Consequently, still relatively high numbers of $\mathrm{PIB}^{-}$scans were seen in patients with a clinical AD diagnosis (39\%), and $\mathrm{PIB}^{+}$scans in patients with a clinical diagnosis of FTD (28\%), DLB (80\%), "dementia-other" (30\%), MCI (57\%), and SMC 
Table 1

Demographic and clinical characteristics according to clinical diagnosis prior to PET

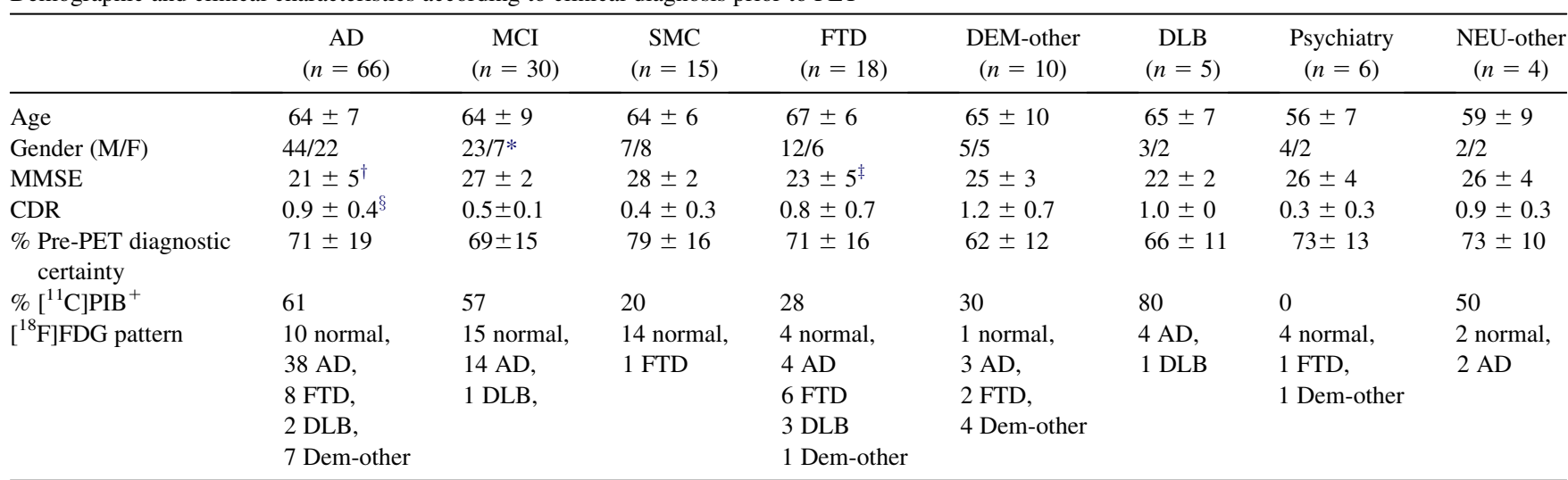

Data are presented as mean \pm SD unless indicated otherwise. Differences between groups were assessed using ANOVA with post hoc Bonferroni tests (age and MMSE), $\chi^{2}$ tests (gender), and Kruskal-Wallis with post hoc Mann-Whitney $U$ tests (CDR). AD, Alzheimer's disease; MCI, mild cognitive impairment; SMC, subjective memory complaints; FTD, frontotemporal dementia; DEM-other, dementia-other; DLB, dementia with Lewy bodies; NEU-other, neurologyother; M, male; F, female; MMSE, Mini-Mental State Examination; CDR, clinical dementia rating.

$*$ MCI $>$ SMC: $p<.05$

${ }^{\dagger} \mathrm{AD}<\mathrm{MCI}$, SMC, and psychiatry: $p<0.05$.

${ }^{\ddagger} \mathrm{FTD}<\mathrm{SMC}: p<.05$.

${ }^{\S} \mathrm{AD}>\mathrm{MCI}, \mathrm{SMC}$, and psychiatry: $p<.05$.

(20\%). Furthermore, $\left[{ }^{18} \mathrm{~F}\right] \mathrm{FDG}$ uptake patterns matched the clinical diagnosis of $\mathrm{AD}$ in $58 \%$ and of FTD in $33 \%$ of cases. $\left[{ }^{18} \mathrm{~F}\right] \mathrm{FDG}$ scans were normal in $93 \%$ of SMC patients.

\subsection{Change of diagnosis}

The clinical diagnosis changed in 35 of the 154 patients (23\%) after disclosing PET results. Figure 1 shows an overview of clinical diagnoses and corresponding diagnostic certainty before and after PET for all dementia patients. In patients with a clinical diagnosis of $\mathrm{AD}(n=66)$, the diagnosis remained $\mathrm{AD}$ in $67 \%$ and was changed in $33 \%$ into either FTD (17\%), "dementia-other" $(6 \%)$, psychiatry $(5 \%)$, DLB (3\%), neurology-other (2\%), or vascular dementia $(2 \%)$. Figure 2 shows an illustrative patient whose clinical diagnosis changed from $\mathrm{AD}$ to $\mathrm{CBD}$ after revelation of a $\left[{ }^{11} \mathrm{C}\right] \mathrm{PIB}^{-}$scan and a $\left[{ }^{18} \mathrm{~F}\right] \mathrm{FDG}$ pattern suggestive of CBD. A clinical diagnosis of FTD $(n=18)$ remained FTD in $61 \%$ of cases, with the remaining $39 \%$ changing into AD (22\%), SMC (6\%), DLB (6\%), or psychiatry (6\%) after PET. The diagnosis of patients in the "dementia-other" category $(n=10)$ changed to AD in 2 patients $(20 \%)$, and a clinical diagnosis of DLB $(n=5)$ was changed to AD in 1 case $(20 \%)$ after PET. Two patients initially diagnosed as psychiatric or "neurology-other" were classified as FTD patients after PET. All clinical diagnoses of SMC or MCI, by definition, remained unchanged after PET.

\subsection{Diagnostic certainty}

For all patients together, diagnostic certainty increased from $71 \pm 17 \%$ before PET to $87 \pm 16 \%$ after PET $(p<.001)$. Diagnostic confidence prior to PET was lower for diagnoses that changed after PET $(62 \pm 18 \%)$ compared with those that remained unchanged $(73 \pm 15 \%, p<.05)$. Also, diagnostic confidence prior to PET was higher in patients with a clinical AD diagnosis who showed $\mathrm{PIB}^{+}$PET scans $(75 \pm 16 \%)$ compared with those who showed $\mathrm{PIB}^{-}$ scans $(64 \pm 20 \%, p<.05)$. A change in clinical diagnosis only occurred when diagnostic confidence prior to PET was $<90 \%$ (Figure 1). Percent change in diagnosis after PET increased with lower pre-PET diagnostic confidence of the clinician (Figure 3).

\subsection{Contribution of $\left[{ }^{11} \mathrm{C}\right] P I B$ and $\left[{ }^{18} F\right] F D G$ to diagnostic process}

In patients whose diagnosis changed after PET, 7 were $\mathrm{PIB}^{+}$and 28 were $\mathrm{PIB}^{-}$. Corresponding patterns of $\left[{ }^{18} \mathrm{~F}\right]$ FDG uptake fitted best to AD (12 cases), FTD (9 cases), DLB ( 2 cases), and dementia-other ( 2 cases), or were considered normal (10 cases). As shown in Table 2, combined $\left[{ }^{11} \mathrm{C}\right]$ PIB and $\left[{ }^{18} \mathrm{~F}\right] \mathrm{FDG}$ contributed most often to the diagnosis (104 cases), followed by $\left[{ }^{11} \mathrm{C}\right] \mathrm{PIB}$ only (29 cases) and $\left[{ }^{18} \mathrm{~F}\right] \mathrm{FDG}$ only (11 cases).

\subsection{Utility of $\left[{ }^{11} \mathrm{C}\right] P I B$ and $\left[{ }^{18} \mathrm{~F}\right] F D G$}

$\left[{ }^{11} \mathrm{C}\right] \mathrm{PIB}$ provided information that improved the clinicians understanding of a patient's disease in $125(81 \%)$ patients, whereas, for $\left[{ }^{18} \mathrm{~F}\right] \mathrm{FDG}$, this was the case in 98 (64\%) patients (refer to supplementary figure). $\left[{ }^{11} \mathrm{C}\right] \mathrm{PIB}$ and $\left[{ }^{18} \mathrm{~F}\right] \mathrm{FDG}$ each confused the clinician in $8(6 \%)$ and $12(10 \%)$ cases, respectively. $\left[{ }^{18} \mathrm{~F}\right] \mathrm{FDG}$ more often (43 cases, 34\%) had only little or no effect on the clinician's comprehension of a patient's disease than $\left[{ }^{11} \mathrm{C}\right] \mathrm{PIB}$ (20 cases, 16\%). 


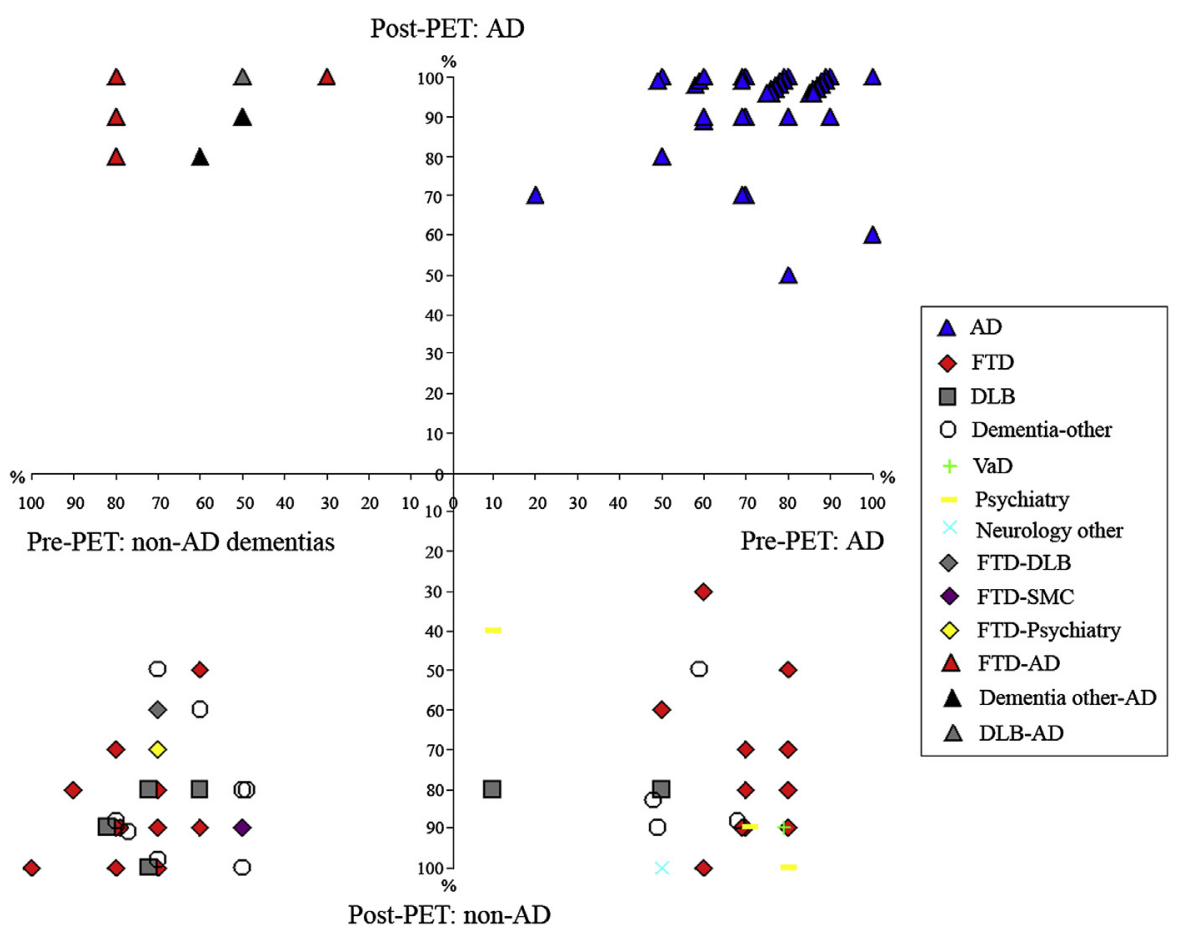

Fig. 1. Scatterplot shows diagnosis data before and after PET for all dementia patients $(n=99)$. Patients in the upper right quadrant were diagnosed with AD at both baseline and after disclosure of PET results. Patients in the lower left quadrant were consistently diagnosed with a non-AD type of dementia. Patients in the left upper quadrant had a clinical diagnosis of a non-AD type of dementia prior to PET, but their diagnoses changed to AD after PET. In the right lower quadrant, clinically diagnosed AD patients are presented, whose diagnoses were changed after PET. The legend specifies the direction of diagnostic changes. The X-and Y-axes represent the confidence levels of the clinicians in the diagnosis before and after PET, respectively. AD, Alzheimer's disease; FTD, frontotemporal dementia; DLB, dementia with Lewy bodies; VaD, vascular dementia; SMC, subjective memory complaints.

\subsection{Clinical follow-up}

Two-year clinical follow-up data were available for 39 patients. Six of 7 patients with MCI and $\left[{ }^{11} \mathrm{C}\right] \mathrm{PIB}^{+} \mathrm{PET}$ scans progressed to AD during follow-up, of whom 5 had a baseline $\left[{ }^{18} \mathrm{~F}\right] \mathrm{FDG}$ scan suggestive of $\mathrm{AD}$ (Table 3). None of the $5 \mathrm{MCI}$ patients with $\left[{ }^{11} \mathrm{C}\right] \mathrm{PIB}^{-}$and normal $\left[{ }^{18}\right.$ F]FDG PET scans converted to AD. SMC patients did not convert during follow-up. Post-PET diagnosis changed in only 1 of 23 dementia patients (4\%) (refer to supplementary table).

\section{Discussion}

In this study we have investigated the added value of combined $\left[{ }^{11} \mathrm{C}\right]$ PIB and $\left[{ }^{18} \mathrm{~F}\right] \mathrm{FDG}$ PET in the diagnostic process in a large sample of patients from a specialized memory clinic. The main result was that molecular imaging is indeed of additional value over standard diagnostic workup, given that $23 \%$ of the initial clinical diagnoses changed and that diagnostic confidence increased after PET. The lower the diagnostic certainty prior to PET, the larger the percent change in diagnosis after PET. Two-year clinical follow-up in a small subset of patients $(n=39)$ showed that PET predicted progression to $\mathrm{AD}$ in MCI patients and that the clinical dementia diagnoses established after PET remained unchanged in $96 \%$ of cases. Application of $\left[{ }^{11} \mathrm{C}\right] \mathrm{PIB}$ and $\left[{ }^{18}\right.$ F $]$ FDG PET seems therefore most useful when confidence in a dementia diagnosis is low, and to increase prognostic certainty in patients with MCI.

There was a frequent mismatch between clinical diagnosis and PET findings in this study. Absence of $\left[{ }^{11} \mathrm{C}\right] \mathrm{PIB}$ binding in clinically diagnosed $\mathrm{AD}$ patients is a common finding, but in general this is less than the 39\% observed in the present study [15]. False negative findings cannot be ruled out, as $\left[{ }^{11} \mathrm{C}\right] \mathrm{PIB}$ PET may not be able to detect more soluble species of $A \beta-42$ or atypical amyloid deposits [36]. This is rare, however, and it is more likely that these patients present with an AD-like phenotype that originates from non-amyloidogenic neuropathology. On the other hand, $\left[{ }^{11} \mathrm{C}\right] \mathrm{PIB}$-positive scans are regularly observed in patients with non-AD dementias, particularly in FTD and in DLB $[16,22,24]$. Autopsy studies in DLB patients have proven that these are not false positive findings but truly reflect AD pathology, next to the presence of Lewy bodies [25]. With respect to FTD, it is known from postmortem studies that about $15 \%-20 \%$ of clinical FTD patients actually have AD [37]. These patients potentially mimic an FTD clinical syndrome that is actually driven by AD pathology, also known as "the frontal variant of AD" [38]. Alternatively, comorbid FTD and AD pathology may be present, with FTD pathology as the force driving the clinical presentation and amyloid pathology as a byproduct of aging. In the present study, clinicians tended to use $\left[{ }^{11} \mathrm{C}\right]$ PIB PET mostly 


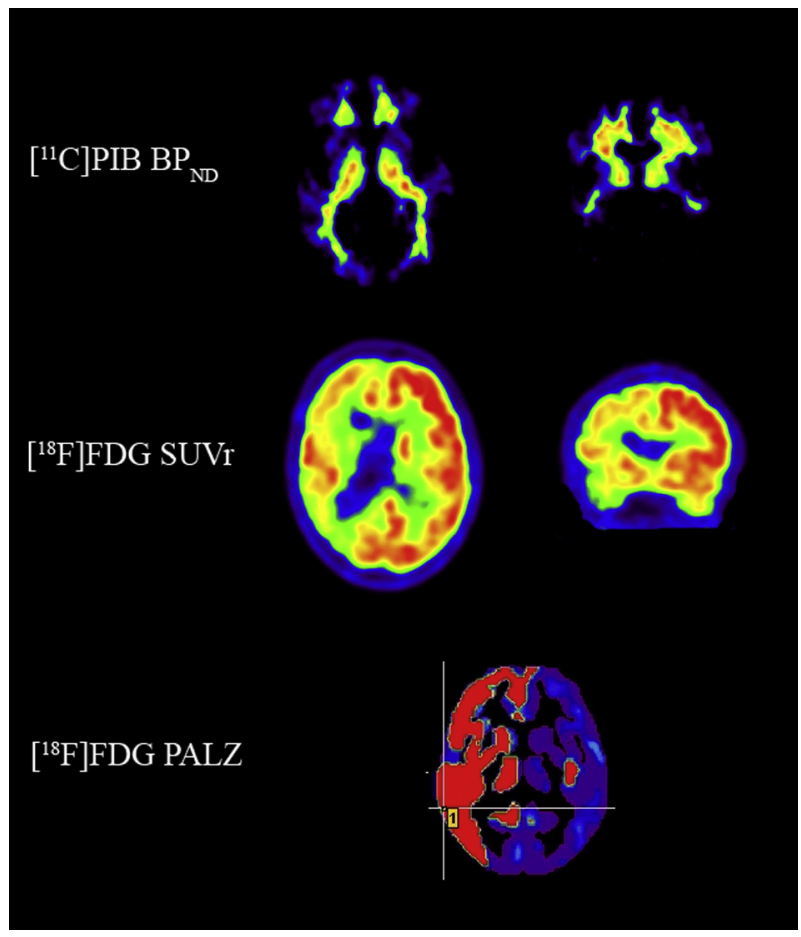

Fig. 2. Example of a 59-year-old man who visited the memory clinic for a second opinion. He presented with memory problems and spatial disorientation. This was confirmed by his spouse who also mentioned several behavioral problems, including aggression and apathy. Neuropsychologic testing revealed visuospatial disturbances, memory deficits, and low MMSE (22) and CAMCOG (80) scores. Frontotemporoparietal brain atrophy was observed on MRI, most pronounced in the right hemisphere. Differential diagnosis after the multidisciplinary consensus meeting consisted of: (1) atypical Alzheimer's disease (AD); (2) corticobasal degeneration (CBD); or (3) behavioral variant frontotemporal dementia. For this study, the probability diagnosis was set to $\mathrm{AD}$ with a diagnostic certainty of 50\%. $\left[{ }^{11} \mathrm{C}\right] \mathrm{PIB}$ PET showed predominantly white matter binding and the diagnosis of $A D$ is therefore highly unlikely. $\left[{ }^{18} \mathrm{~F}\right] \mathrm{FDG}$ PET displayed extremely asymmetric metabolic impairment in the right hemisphere with involvement of the basal ganglia. This pattern is suggestive for CBD. According to these PET findings, the clinician changed the diagnosis to $\mathrm{CBD}$ with a diagnostic certainty of $90 \%$. Two-year follow-up revealed cognitive deterioration (MMSE declined to 12), further progression of brain atrophy and a disease course that fits the diagnosis of CBD.

to rule out $\mathrm{AD}$, which seems justified according to the aforementioned neuropathologic findings.

Unlike $\left[{ }^{11} \mathrm{C}\right] \mathrm{PIB},\left[{ }^{18} \mathrm{~F}\right] \mathrm{FDG}$ does not provide dichotomous information, as metabolic impairment occurs in many brain disorders that cause cognitive deterioration [10]. $\left[{ }^{18}\right.$ F]FDG PET, however, can be used to identify patterns of cerebral glucose hypometabolism that characterize several neurodegenerative diseases. Due to its close relation with neuronal function, and therefore cognitive status, $\left[{ }^{18}\right.$ F]FDG PET can be helpful in diagnostic dilemmas [10]. In the present study, discrepancies between clinical diagnosis and $\left[{ }^{18}\right.$ F]FDG PET findings were common. This may be explained by diagnostic misclassification or by patients with atypical clinical presentations and equivalent patterns of glucose hypometabolism or by patients with an typical clinical presentation but atypical $\left[{ }^{18} \mathrm{~F}\right] \mathrm{FDG}$ uptake.

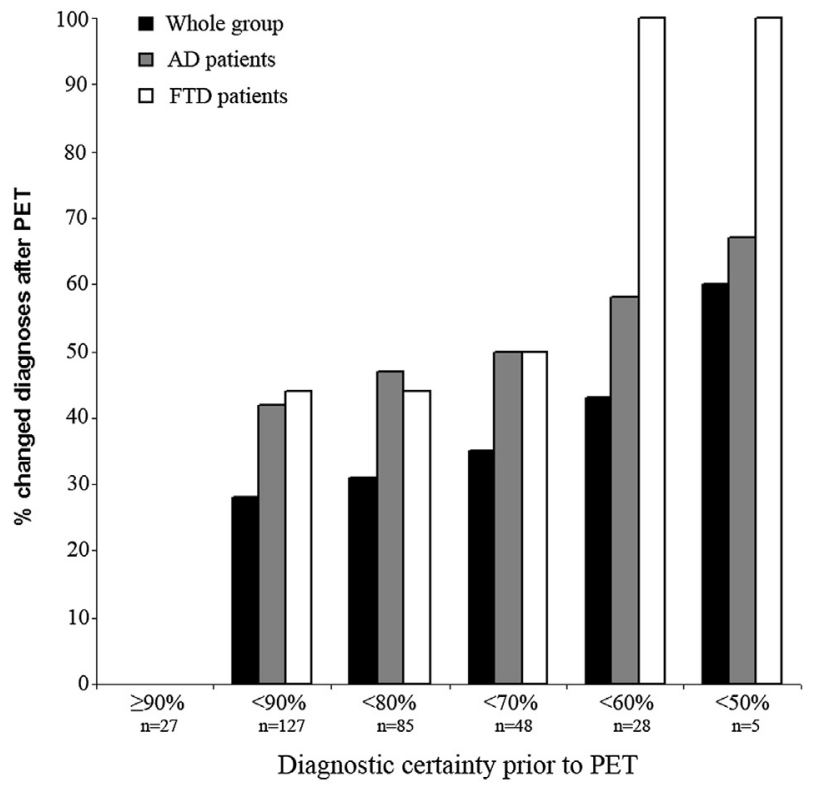

Fig. 3. Bar diagrams indicating the percentage of diagnoses that changed after disclosing PET results as a function of diagnostic certainty prior to PET. Abbreviations: AD, Alzheimer's disease; FTD, frontotemporal dementia.

The case presented in Figure 2 illustrates the synergistic effect of using both pathophysiologic and metabolic tracers. Indeed, clinicians indicated that the combination of $\left[{ }^{11} \mathrm{C}\right] \mathrm{PIB}$ and $\left[{ }^{18} \mathrm{~F}\right] \mathrm{FDG}$ most often contributed to the diagnosis, followed by $\left[{ }^{11} \mathrm{C}\right] \mathrm{PIB}$ alone and $\left[{ }^{18} \mathrm{~F}\right] \mathrm{FDG}$ alone. Cases in which $\left[{ }^{11} \mathrm{C}\right] \mathrm{PIB}$ was decisive were mainly initial clinical diagnoses of SMC, MCI, or AD, whereas $\left[{ }^{18} \mathrm{~F}\right] \mathrm{FDG}$ was essential in some cases with a clinical diagnosis of FTD, DLB, or psychiatry. Based on the present study, combining $\left[{ }^{11} \mathrm{C}\right] \mathrm{PIB}$ and $\left[{ }^{18}\right.$ F]FDG PET seems most useful in patients with low diagnostic certainty after standard diagnostic work-up. Costeffectiveness of both $\left[{ }^{11} \mathrm{C}\right] \mathrm{PIB}$ and $\left[{ }^{18} \mathrm{~F}\right] \mathrm{FDG}$ in a memory clinic setting have yet to be proven, but, assuming that PET improves diagnostic accuracy, this will be greatly enhanced by the availability of disease-modifying agents in the future.

Table 2

Contribution of $\left[{ }^{11} \mathrm{C}\right] \mathrm{PIB}$ and $\left[{ }^{18} \mathrm{~F}\right] \mathrm{FDG}$ to diagnosis

\begin{tabular}{lrccc}
\hline $\begin{array}{l}\text { Diagnosis } \\
\text { prior to PET }\end{array}$ & $\begin{array}{c}{\left[{ }^{11} \mathrm{C}\right] \mathrm{PIB}+} \\
{\left[{ }^{18} \mathrm{~F}\right] \mathrm{FDG}}\end{array}$ & $\begin{array}{c}{\left[{ }^{11} \mathrm{C}\right] \mathrm{PIB}} \\
\text { only }\end{array}$ & $\begin{array}{c}{\left[{ }^{18} \mathrm{~F}\right] \mathrm{FDG}} \\
\text { only }\end{array}$ & $\begin{array}{c}\text { None } \\
\text { of both }\end{array}$ \\
\hline Whole group & $104 / 68 \%$ & $29 / 28 \%$ & $11 / 7 \%$ & $10 / 6 \%$ \\
AD & $45 / 68 \%$ & $15 / 23 \%$ & $3 / 5 \%$ & $3 / 5 \%$ \\
MCI & $19 / 63 \%$ & $8 / 27 \%$ & $1 / 3 \%$ & $2 / 7 \%$ \\
SMC & $7 / 47 \%$ & $5 / 33 \%$ & $1 / 7 \%$ & $2 / 13 \%$ \\
FTD & $14 / 78 \%$ & $0 / 0 \%$ & $3 / 17 \%$ & $1 / 6 \%$ \\
Dementia-other & $8 / 80 \%$ & $0 / 0 \%$ & $1 / 10 \%$ & $1 / 10 \%$ \\
DLB & $4 / 80 \%$ & $0 / 0 \%$ & $1 / 20 \%$ & $0 / 0 \%$ \\
Psychiatry & $4 / 67 \%$ & $1 / 17 \%$ & $1 / 17 \%$ & $0 / 0 \%$ \\
Neurology-other & $3 / 75 \%$ & $0 / 0 \%$ & $0 / 0 \%$ & $1 / 25 \%$ \\
\hline
\end{tabular}

Data are presented as number/percent. Neurologists indicated whether both tracers, $\left[{ }^{11} \mathrm{C}\right] \mathrm{PIB}$ alone, $\left[{ }^{18} \mathrm{~F}\right] \mathrm{FDG}$ alone, or none, contributed to the diagnostic process. AD, Alzheimer's disease; $\mathrm{MCI}$, mild cognitive impairment; SMC, subjective memory complaints; FTD, frontotemporal dementia; DLB, dementia with Lewy bodies. 
Table 3

Two-year clinical follow-up of SMC and MCI patients

\begin{tabular}{lllll}
\hline $\mathrm{n}$ & Dx prior to PET & {$\left[{ }^{11} \mathrm{C}\right] \mathrm{PIB}$} & {$\left[{ }^{18} \mathrm{~F}\right] \mathrm{FDG}$} & Dx after 2-year FU \\
\hline 5 & MCI & + & AD & AD \\
1 & MCI & + & Normal & AD \\
1 & MCI & + & Normal & MCI \\
2 & MCI & - & Normal & MCI \\
1 & MCI & - & Normal & FTD \\
1 & MCI & - & Normal & SMC \\
1 & MCI & - & Normal & Psychiatry \\
3 & SMC & - & Normal & SMC \\
1 & SMC & + & Normal & SMC \\
\hline
\end{tabular}

Abbreviations: Dx, diagnosis; FU, follow-up; MCI, mild cognitive impairment; AD, Alzheimer's disease; SMC, subjective memory complaints; FTD, frontotemporal dementia.

The results of our study cannot simply be generalized to a general memory clinic population. These patients had visited a last resort memory clinic, most of them for a second or third opinion. The relatively young age of the patients (64 years, on average) make an initial diagnosis more difficult as clinical presentations tend to overlap between diagnostic categories and this may not be representative for an older sample [1]. Furthermore, a subset of this sample underwent PET for diagnostic purposes because standard diagnostic work-up was not sufficient. All these factors together complicate the interpretation of the present results. In addition, the study design may have affected the outcome as it was mandatory for the neurologists to select a probability diagnosis, even in complex cases that would usually be postponed, when awaiting clinical follow-up and/or additional investigations. Another potential limitation of this study is the lack of postmortem verification, as no autopsy data were available. Alternatively, a subset of patients underwent 2-year clinical follow-up and, in these patients, the post-PET diagnoses remained stable in the dementia patients. Finally, $\left[{ }^{11} \mathrm{C}\right] \mathrm{PIB}$ and $\left[{ }^{18} \mathrm{~F}\right] \mathrm{FDG}$ were always assessed together and the nuclear medicine physician was provided with the clinical differential diagnosis, which may have affected the interpretation of both scans.

In conclusion, in a memory clinic, $\left[{ }^{11} \mathrm{C}\right] \mathrm{PIB}$ and $\left[{ }^{18} \mathrm{~F}\right]$ FDG PET have additional value beyond standard diagnostic work-up. Molecular imaging in this setting is most useful for early diagnosis of $\mathrm{AD}$ and in cases of high diagnostic uncertainty after standard work-up.

\section{Acknowledgment}

This research was performed within the framework of CTMM, the Center for Translational Molecular Medicine (www.ctmm.nl), project LeARN (Grant 02N-101).

\section{References}

[1] Galton CJ, Patterson K, Xuereb JH, Hodges JR. Atypical and typical presentations of Alzheimer's disease: A clinical, neuropsychological, neuroimaging and pathological study of 13 cases. Brain 2000;123:3484-98.

[2] Dubois B, Feldman HH, Jacova C, Dekosky ST, Barberger-Gateau P, Cummings J, et al. Research criteria for the diagnosis of Alzheimer's disease: Revising the NINCDS-ADRDA criteria. Lancet Neurol 2007; 6:734-46.

[3] Albert MS, DeKosky ST, Dickson D, Dubois B, Feldman HH, Fox NC, et al. The diagnosis of mild cognitive impairment due to Alzheimer's disease: Recommendations from the National Institute on Aging-Alzheimer's Association workgroups on diagnostic guidelines for Alzheimer's disease. Alzheimers Dement 2011;7:270-9.

[4] McKhann GM, Knopman DS, Chertkow H, Hyman BT, Jack CR, Kawas $\mathrm{CH}$, et al. The diagnosis of dementia due to Alzheimer's disease: Recommendations from the National Institute on Aging-Alzheimer's Association workgroups on diagnostic guidelines for Alzheimer's disease. Alzheimers Dement 2011;7:263-9.

[5] Rascovsky K, Hodges JR, Knopman D, Mendez MF, Kramer JH, Neuhaus J, et al. Sensitivity of revised diagnostic criteria for the behavioural variant of frontotemporal dementia. Brain 2011;134:2456-77.

[6] McKeith IG, Dickson DW, Lowe J, Emre M, O’Brien JT, Feldman H, et al. Diagnosis and management of dementia with Lewy bodies: Third report of the DLB Consortium. Neurology 2005;65:1863-72.

[7] Chételat G, Desgranges B, de la Sayette V, Viader F, Eustache F, Baron JC. Mild cognitive impairment: Can FDG-PET predict who is to rapidly convert to Alzheimer's disease? Neurology 2003; 60:1374-7.

[8] Landau SM, Harvey D, Madison CM, Reiman EM, Foster NL, Aisen PS, et al. Comparing predictors of conversion and decline in mild cognitive impairment. Neurology 2010;75:230-8.

[9] Drzezga A, Lautenschlager N, Siebner H, Riemenschneider M, Willoch F, Minoshima S, et al. Cerebral metabolic changes accompanying conversion of mild cognitive impairment into Alzheimer's disease: A PET follow-up study. Eur J Nucl Med Mol Imaging 2003;30:1104-13.

[10] Silverman DH, Small GW, Chang CY, Lu CS, Kung De Aburto MA, Chen W, et al. Positron emission tomography in evaluation of dementia: Regional brain metabolism and long-term outcome. JAMA 2001; 286:2120-7.

[11] Ishii K, Sakamoto S, Sasaki M, Kitagaki H, Yamaji S, Hashimoto M, et al. Cerebral glucose metabolism in patients with frontotemporal dementia. J Nucl Med 1998;39:1875-8.

[12] Ishii K, Imamura T, Sasaki M, Yamaji S, Sakamoto S, Kitagaki H, et al. Regional cerebral glucose metabolism in dementia with Lewy bodies and Alzheimer's disease. Neurology 1998;51:125-30.

[13] Ng S, Villemagne VL, Berlangieri S, Lee ST, Cherk M, Gong SJ, et al. Visual assessment versus quantitative assessment of 11C-PIB PET and 18F-FDG PET for detection of Alzheimer's disease. J Nucl Med 2007; 48:547-52.

[14] Tolboom N, van der Flier WM, Boverhoff J, Yaqub M, Wattjes MP, Raijmakers PG, et al. Molecular imaging in the diagnosis of Alzheimer's disease: Visual assessment of [11C]PIB and [18F]FDDNP PET images. J Neurol Neurosurg Psychiatry 2010;81:882-4.

[15] Klunk WE, Engler H, Nordberg A, Wang Y, Blomqvist G, Holt DP, et al. Imaging brain amyloid in Alzheimer's disease with Pittsburgh Compound-B. Ann Neurol 2004;55:306-19.

[16] Leyton CE, Villemagne VL, Savage S, Pike KE, Ballard KJ, Piguet O, et al. Subtypes of progressive aphasia: application of the International Consensus Criteria and validation using $\beta$-amyloid imaging. Brain 2011;134:3030-43.

[17] Tolboom N, Yaqub M, van der Flier WM, Boellaard R, Luurtsema G, Windhorst $\mathrm{AD}$, et al. Detection of Alzheimer pathology in vivo using both 11C-PIB and 18F-FDDNP PET. J Nucl Med 2009;50:191-7.

[18] Morris JC, Roe CM, Grant EA, Head D, Storandt M, Goate AM, et al. Pittsburgh compound B imaging and prediction of progression from cognitive normality to symptomatic Alzheimer disease. Arch Neurol 2009;66:1469-75.

[19] Okello A, Koivunen J, Edison P, Archer HA, Turkheimer FE, Någren K, et al. Conversion of amyloid positive and negative MCI to AD over 3 years: An 11C-PIB PET study. Neurology 2009;73:754-60.

[20] Forsberg A, Engler H, Almkvist O, Blomquist G, Hagman G, Wall A, et al. PET imaging of amyloid deposition in patients with mild cognitive impairment. Neurobiol Aging 2008;29:1456-65. 
[21] Koivunen J, Scheinin N, Virta JR, Aalto S, Vahlberg T, Någren K, et al. Amyloid PET imaging in patients with mild cognitive impairment: A 2-year follow-up study. Neurology 2011;76:1085-90.

[22] Rabinovici GD, Rosen HJ, Alkalay A, Kornak J, Furst AJ, Agarwal N, et al. Amyloid vs FDG-PET in the differential diagnosis of AD and FTLD. Neurology 2011;77:2034-42.

[23] Lee JH, Kim SH, Kim GH, Seo SW, Park HK, Oh SJ, et al. Identification of pure subcortical vascular dementia using 11C-Pittsburgh compound B. Neurology 2011;77:18-25.

[24] Gomperts SN, Rentz DM, Moran E, Becker JA, Locascio JJ, Klunk WE, et al. Imaging amyloid deposition in Lewy body diseases. Neurology 2008;71:903-10.

[25] Harding AJ, Halliday GM. Cortical Lewy body pathology in the diagnosis of dementia. Acta Neuropathol 2001;102:355-63.

[26] Ossenkoppele R, Tolboom N, Foster-Dingley JC, Adriaanse SF, Boellaard R, Yaqub M, et al. Longitudinal imaging of Alzheimer pathology using [(11)C]PIB, [(18)F]FDDNP and [ (18)F]FDG PET. Eur J Nucl Med Mol Imaging 2012;39:990-1000.

[27] McKhann G, Drachman D, Folstein M, Katzman R, Price D, Stadlan EM. Clinical diagnosis of Alzheimer's disease: report of the NINCDS-ADRDA Work Group under the auspices of Department of Health and Human Services Task Force on Alzheimer's Disease. Neurology 1984;34:939-44.

[28] Litvan I, Agid Y, Calne D, Campbell G, Dubois B, Duvoisin RC, et al. Clinical research criteria for the diagnosis of progressive supranuclear palsy (Steele-Richardson-Olszewski syndrome): Report of the NINDS-SPSP international workshop. Neurology 1996;47:1-9.

[29] Neary D, Snowden JS, Gustafson L, Passant U, Stuss D, Black S, et al. Frontotemporal lobar degeneration: A consensus on clinical diagnostic criteria. Neurology 1998;51:1546-54.
[30] Riley D, Lang A. Clinical diagnostic criteria: Corticobasal degeneration and related disorders. Adv Neurol 2000;:8229-34.

[31] Petersen RC, Doody R, Kurz A, Mohs RC, Morris JC, Rabins PV, et al. Current concepts in mild cognitive impairment. Arch Neurol 2001; 58:1985-92.

[32] Svarer C, Madsen K, Hasselbalch SG, Pinborg LH, Haugbøl S, Frøkjaer VG, et al. MR-based automatic delineation of volumes of interest in human brain PET images using probability maps. Neuroimage 2005;24:969-79.

[33] Wu Y, Carson RE. Noise reduction in the simplified reference tissue model for neuroreceptor functional imaging. J Cereb Blood Flow Metab 2002;22:1440-52.

[34] Yaqub M, Tolboom N, Boellaard R, van Berckel BN, van Tilburg EW, Luurtsema G, et al. Simplified parametric methods for [11C]PIB studies. Neuroimage 2008;42:76-86.

[35] Herholz K, Salmon E, Perani D, Baron JC, Holthoff V, Frölich L, et al. Discrimination between Alzheimer dementia and controls by automated analysis of multicenter FDG PET. Neuroimage 2002; 17:302-16.

[36] Leinonen V, Alafuzoff I, Aalto S, Suotunen T, Savolainen S, Någren K, et al. Assessment of beta-amyloid in a frontal cortical brain biopsy specimen and by positron emission tomography with carbon 11-labeled Pittsburgh Compound B. Arch Neurol 2008; 65:1304-9.

[37] Forman MS, Farmer J, Johnson JK, Clark CM, Arnold SE, Coslett HB, et al. Frontotemporal dementia: Clinicopathological correlations. Ann Neurol 2006;59:952-62.

[38] Johnson JK, Head E, Kim R, Starr A, Cotman CW. Clinical and pathological evidence for a frontal variant of Alzheimer disease. Arch Neurol 1999;56:1233-9.

\section{Did you know?}

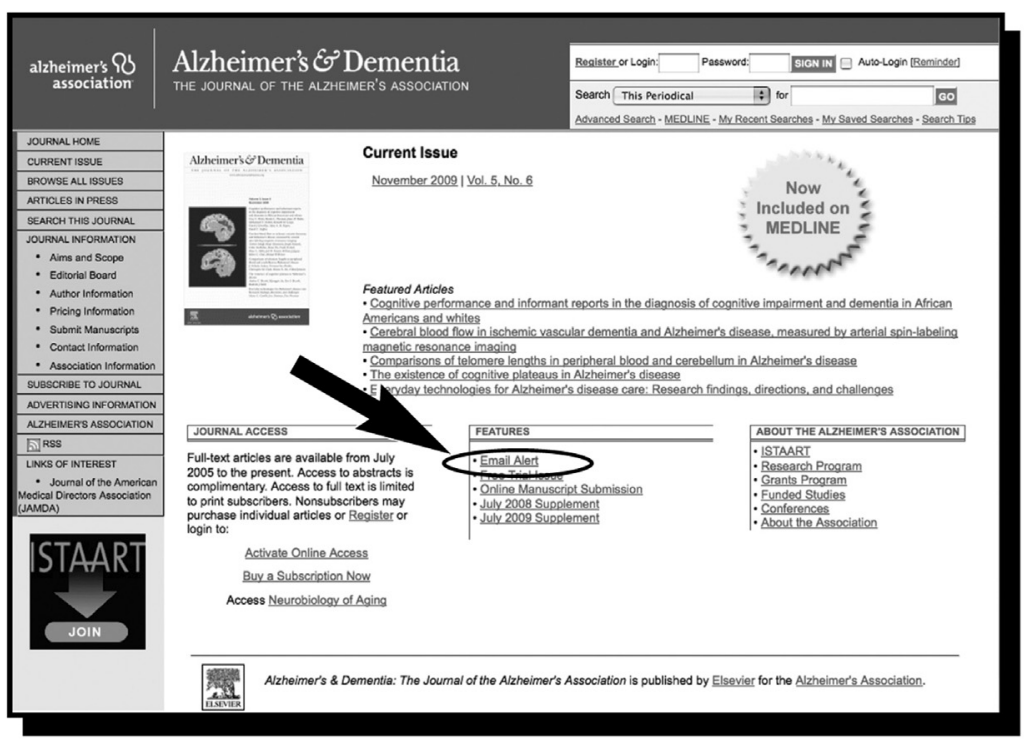

You can get Alzheimer's \& Dementia tables of contents by email. 